\title{
Case Report \\ The First Ever Reported Case of Primary Synovial Sarcoma of Scalp
}

\author{
Biplab Mishra, ${ }^{1}$ Saurabh Singhal, ${ }^{1}$ Deepak Prakash Bhirud, ${ }^{1}$ \\ Nitesh Kumar, ${ }^{1}$ and Saumyaranjan Mallick ${ }^{2}$ \\ ${ }^{1}$ Department of Surgical Disciplines, All India Institute of Medical Sciences, New Delhi 110029, India \\ ${ }^{2}$ Department of Pathology, All India Institute of Medical Sciences, New Delhi 110029, India
}

Correspondence should be addressed to Saurabh Singhal; drsaurabhsinghal@gmail.com

Received 27 January 2016; Revised 5 June 2016; Accepted 13 June 2016

Academic Editor: Yueh-Bih Tang

Copyright (C) 2016 Biplab Mishra et al. This is an open access article distributed under the Creative Commons Attribution License, which permits unrestricted use, distribution, and reproduction in any medium, provided the original work is properly cited.

\begin{abstract}
Synovial sarcomas are a rare entity with predilection for extremities and joints. The literature suggests that these tumours are rare in the head and neck region. Very few authors have reported their origin in head. Among the ones occurring in the head region, most of them are found to originate from the parotid area. According to our extensive review of available literature, there has been no reported case of the primary case of synovial sarcoma originating from the scalp convexity. We hereby report one such case in a young female which, by far to the best of our knowledge, is the first ever reported case of a synovial sarcoma occurring on the scalp. The tumour is also the largest ever reported in the literature and posed a great surgical and diagnostic challenge to our team. Through this paper, we recommend that synovial sarcoma should be included as a very rare yet possible differential diagnosis for the scalp tumours.
\end{abstract}

\section{Introduction}

Soft tissue sarcomas are rare malignancies arising from embryonic mesenchymal cells, thus having varied origin and a wide range of subtypes. They constitute about $1 \%$ of all malignancies with an incidence of about 20 per million people and about $8 \%$ of cancers in children [1]. Synovial sarcomas are rare subtypes of high grade soft tissue sarcomas and are associated with poorer survival [2]. They have a predilection for extremities and joints and are very rare in head and neck region. There are less than 200 reported cases of head and neck synovial sarcomas in the literature, most of which show predilection for neck and parotid [2,3]. We present the case of a scalp tumour, which after great diagnostic dilemma proved to be a synovial sarcoma.

\section{Case History}

A 25-year-old woman from a remote village of India presented to the surgery clinic of our hospital with complaint of recurrent swelling on her scalp for the last 6 years. Insidious in onset, painless, and gradually progressive in size, the swelling first occurred on her midscalp and gradually progressed in size over the next 1 year. It was first excised locally by a private practitioner at her hometown. She remained asymptomatic for about two years when she had a recurrence of swelling followed by a second surgical excision at a local hospital. No histopathological diagnoses were made on the excised specimens due to limitation of resources. The patient remained asymptomatic for about a year before she had the second recurrence at the same site but with a more rapid growth and presence of ulceration. She was referred to our tertiary level multispecialty centre for management.

The patient presented to us with a huge swelling rapidly increasing in size. The swelling was large and boggy and was associated with heaviness of the head, pustular discharge, and on and off fever for the last 4 months.

There were no neurological deficits or metastatic symptoms. The patient was married and nulliparous with no obstetric or gynaecologic complaints. There was no significant family history. The patient was depressed due to 

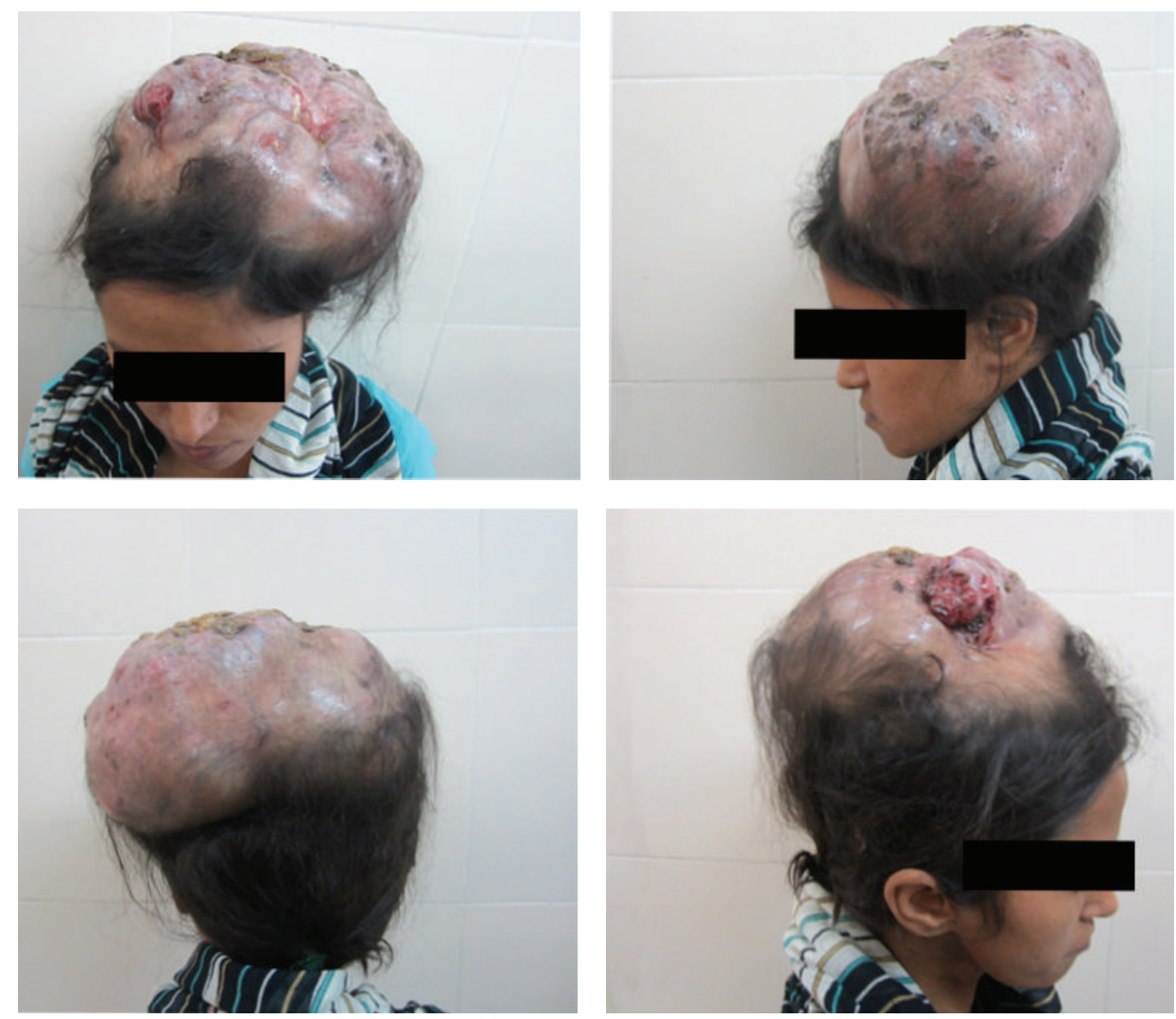

FIGURE 1: The large bosselated tumour covering almost the whole scalp with multiple ulcers and pus pockets.

associated disfigurement and marital problems due to her disease. Viral markers and toxic profile were negative.

Examination revealed a large $25 \times 18 \mathrm{~cm}$ lobulated, bosselated swelling covering almost the whole scalp with focal ulceration and alopecia. There were multiple pus pockets with foul smelling blood stained pus discharge. Swelling was mildly tender (Figure 1).

There was cervical lymphadenopathy with multiple mobile, nontender, firm lymph nodes in the left submandibular region and posterior triangle. The rest of the general physical and systemic examinations were within normal limits. She had a pulse rate of 89 per minute and blood pressure of $112 / 78 \mathrm{mmHg}$. She had a low grade fever $\left(99.2^{\circ} \mathrm{F}\right)$.

Multiple cultures were obtained. Pus cultures revealed methicillin sensitive Staphylococcus aureus (MSSA). Her blood and urine cultures and further wound swab cultures came sterile. Her fever responded to antibiotics.

Multiple trucut biopsies taken from the scalp swelling came inconclusive. Incisional biopsy was thus taken which showed fibrocollagenous tissue with chronic inflammatory infiltrate and extensive areas of necrosis. There was no evidence of malignancy in any of the histopathological reports. Excisional biopsy of posterior cervical lymph nodes suggested reactive changes.

The patient underwent contrast-enhanced computed tomography (CECT) of head and neck with 3-dimensional reconstruction (Figures 2(a) and 2(b)). Reports suggested a large and highly vascular heterogeneous tumour on scalp with necrotic and cystic areas. There were clear surgical planes with underlying cranial bones with no signs of invasion.

With the provisional diagnosis of recurrent scalp tumour with probable malignant or inflammatory pathology, excision under general anaesthesia was planned. Challenges were to achieve negative surgical margins in a highly vascular and huge scalp tumour and to cover the large scalp defect thus created.

With the patient in supine position, the tumour was well painted and segregated with sterile drapes. The head was placed flexed for adequate exposure of the tumour tissue. With high vascularity of the tumour, it was dissected off the cranium with haemostatic sutures applied all around on the tumour edge and with a $2 \mathrm{~cm}$ margin on the normal scalp tissue. The raw area thus created was covered with split thickness skin graft harvested from the left thigh. The procedure was uneventful with less than $300 \mathrm{~mL}$ of blood loss (Figure 3).

The patient made uneventful recovery and was discharged on postoperative day seven with almost $90 \%$ graft uptake. Two-week follow-up revealed healthy graft tissue (Figure 4).

Histopathology of the excised specimen revealed a solid cystic tumour with areas of necrosis. The size of the tumour in excised specimen was $24.5 \mathrm{~cm} \times 12 \mathrm{~cm} \times 10.5 \mathrm{~cm}$ (Figure 5). The tumour consisted of round to oval cells, moderate pleomorphism, and increased mitosis. Tumour cells were 


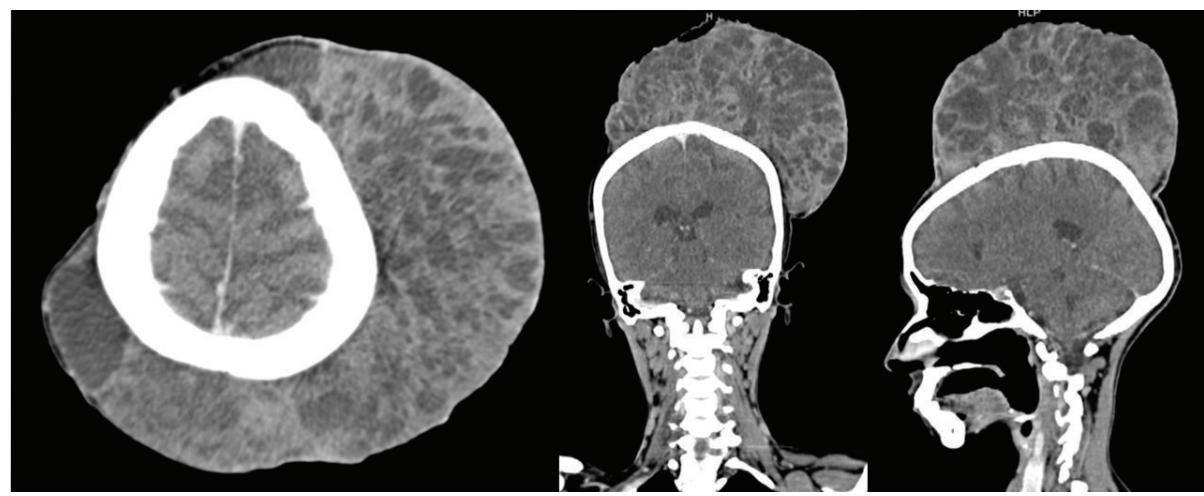

(a)

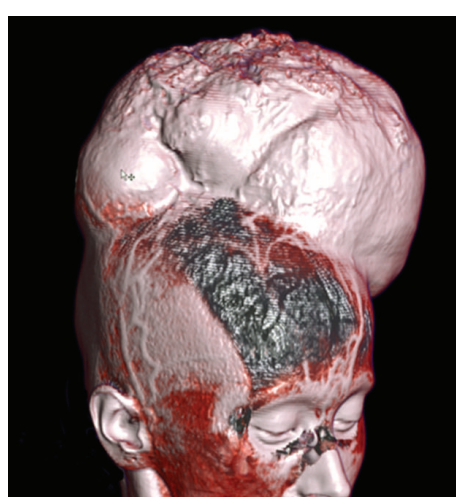

(b)

FIGURE 2: Computed tomography (CT) scan with 3D reconstruction showing highly vascular tumour with clean surgical plane with underlying calvarium.
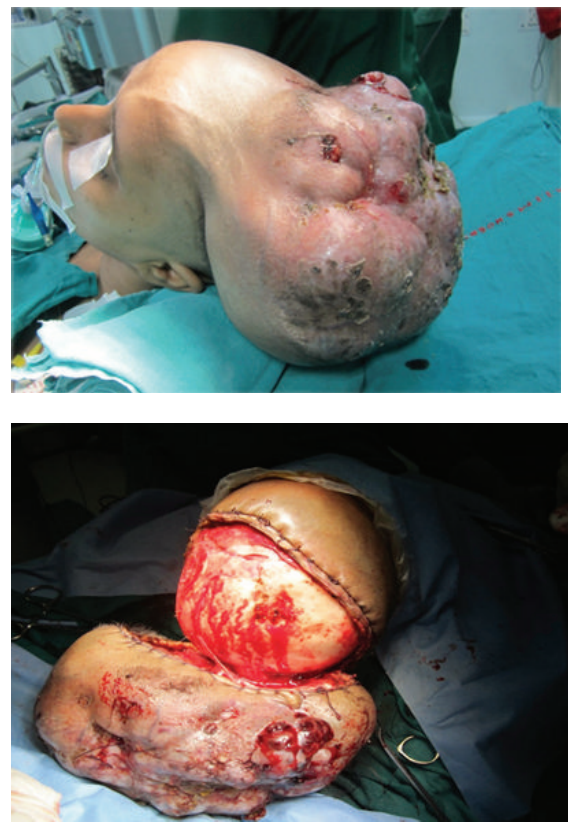
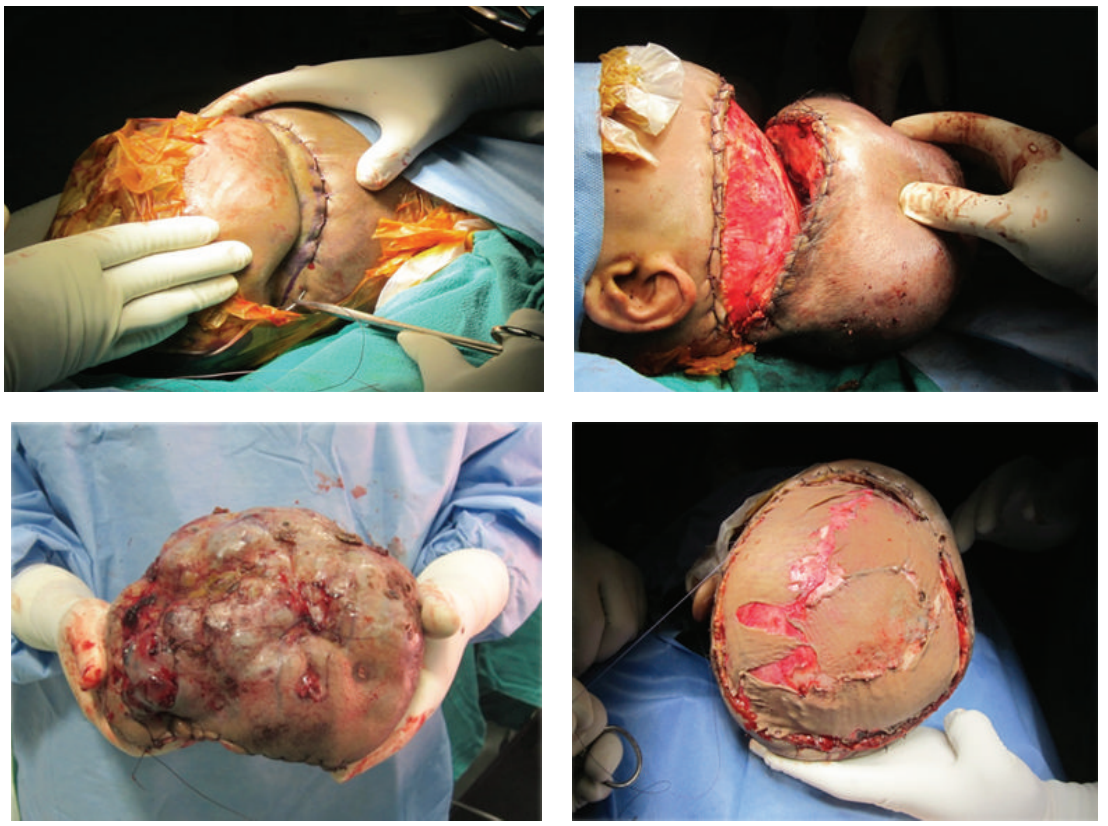

FIgURE 3: Surgical excision of tumour and coverage of scalp with split thickness skin graft. Note that, with the use of hemostatic sutures, blood loss could be minimised.

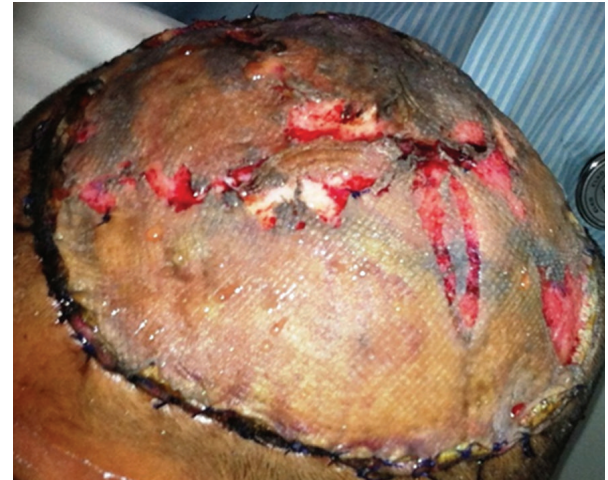

FIGURE 4: Two-week follow-up revealed healthy graft with granulation tissue and $>90 \%$ uptake. immunopositive for vimentin, cytokeratin (focal), Bcl2, and MIC2 while they were negative for chromogranin, synaptophysin, inhibin, calretinin, and alpha-fetoprotein (Figures $6(\mathrm{a})-6(\mathrm{~d}))$. The above findings were suggestive of poorly differentiated synovial sarcoma. Positivity for $\mathrm{t}(\mathrm{X} ; 18)$ translocation was seen in about $30 \%$ of cells and thus supported the diagnosis. All surgical margins were free of tumour.

She received postoperative locoregional radiotherapy after complete take of skin graft and epithelisation of all raw areas. A repeat PET-CT at 24 months showed no focus of recurrence of disease. On a 29-month follow-up after surgery, the patient was asymptomatic with no recurrence (Figure 7). As the graft tissue contraction occurred, she was given temporary cosmetic coverage of the scalp with artificial wigs. Further, tissue expanders are being used to expand 


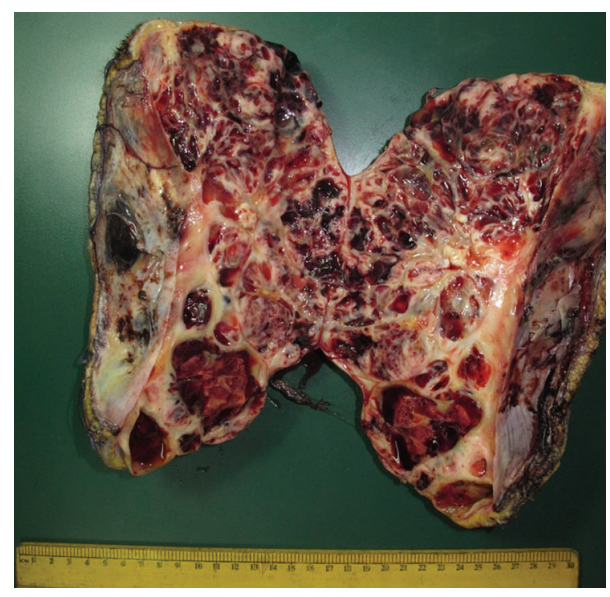

FIGURE 5: Histopathological specimen of excised tissue revealing the large size of the tumour.

the remaining peripheral normal scalp tissue which will be used to cover the bald area (treatment with tissue expander is shown in Figure 7). She is also planned for trial of hair transplantation on the remaining grafted skin lacking hair follicles.

\section{Discussion}

Sarcomas of head and neck origin account for $<10 \%$ of all sarcomas and about $1 \%$ of all primary head and neck malignancies $[2,4,5]$. Soft tissue sarcomas constitute $80 \%$ of all sarcomas [2]. Synovial sarcomas in turn consist of less than $10 \%$ of all soft tissue sarcomas [2]. The peak incidence of synovial sarcoma is in the third decade, common presentation being a young adult presenting with sarcomatous tumour of an extremity [1]. About one-third of synovial sarcomas occur under twenty years of age; however, they still are the second-commonest sarcomas after rhabdomyosarcoma in adolescents and young adults [1].

Synovial sarcoma is a relatively rare subtype of soft tissue sarcoma with histologic resemblance to synovial cells, thus the name. The morphologic subtypes are divided into monophasic and biphasic according to the presence or absence of differentiation into glandular epithelium and a third poorly differentiated subtype. The most characteristic and hallmark genetic alteration is the chromosomal translocation $\mathrm{t}(\mathrm{X} ; 18)(\mathrm{p} 11.2 ; \mathrm{q} 11.2)$ [6]. The SYT gene (Chr 18) fuses with SSX1 (Chr X) to form biphasic tumour while fusion with SSX2 leads to monophasic tumour. The latter is associated with longer metastasis-free survival [7, 8]. Stage, tumour size, tumour location, and age at diagnosis are the major factors predicting cancer-specific survival [9, 10]. Despite pathological grading into differentiated and poorly differentiated varieties, they have propensity to locally invade and metastasize and should always be considered and managed as high grade sarcomas $[9,11]$.

Synovial sarcoma rarely presents on trunk and regions of head and neck. The latter contributes $2.5-3.7 \%$ of all synovial sarcoma cases $[3,12,13]$. The first such case was reported by
Jernstrom in 1954 [14]. Majority of such synovial sarcomas tend to occur in neck region. In a major series of 36 cases along with analysis of another 28 cases reported in the English literature [3], only $1.9 \%$ of all synovial sarcomas occurred in head region and mainly involved temporal and parotid regions, cheek, infratemporal fossa, and mastoid areas. There were rare cases involving other areas of head and none was found to involve convexity of scalp $[3,12,13,15,16]$.

Based on extensive literature search, our case is the largest case of synovial sarcoma of head and neck ever excised $[3,12$, $13,15]$. Before this, the largest tumour ever excised was from cheek and was $18.5 \mathrm{~cm} \times 15 \mathrm{~cm} \times 13.5 \mathrm{~cm}[3,17]$ whereas our tumour was much larger as shown in Figure 5.

Surgery is the mainstay of treatment [18]. However, achieving negative surgical margins in regions of head and neck is very difficult and poses a great challenge to the surgeon. This was a major challenge to our team as well. This results in higher recurrence rates and worse prognosis in head and neck sarcomas [19]. Covering the defect created after excision of large tumours is another challenge. Calvarium has a rich vascular supply and is a potential candidate for split thickness skin graft. Rotational or free flaps are other possible options.

The role of adjuvant therapies is debatable. Chemotherapy takes care of the microscopic cancer cells locally and those disseminated systemically. Locoregional radiotherapy is important to reduce the chances of local recurrence and also takes care of the microscopic or sometimes macroscopic positive surgical margins.

The outcome of a well differentiated tumour with adequate surgical excision and aggressive adjuvant therapies is fairly good with survival rates in the range of $60 \%[2$, 16]. Recurrence is fairly common and close follow-up is required for early detection of recurrence and metastasis, if any.

\section{Conclusion}

As per our extensive search of the literature and the unique presentation of our patient, we can affirmatively say that this is, in most likelihood, the first ever reported case of synovial sarcoma of scalp origin and indeed the largest primary synovial sarcoma of head and neck region ever excised. We emphasise the need of including synovial sarcomas as one of the rare differential diagnoses of head and neck sarcomas.

\section{Abbreviations}

POD: Postoperative day.

\section{Additional Points}

The key message of this paper is to report that this is the first ever reported case of a synovial sarcoma of scalp origin. The authors, thus, recommend the inclusion of synovial sarcoma as one of the rare differential diagnoses for scalp tumours. 


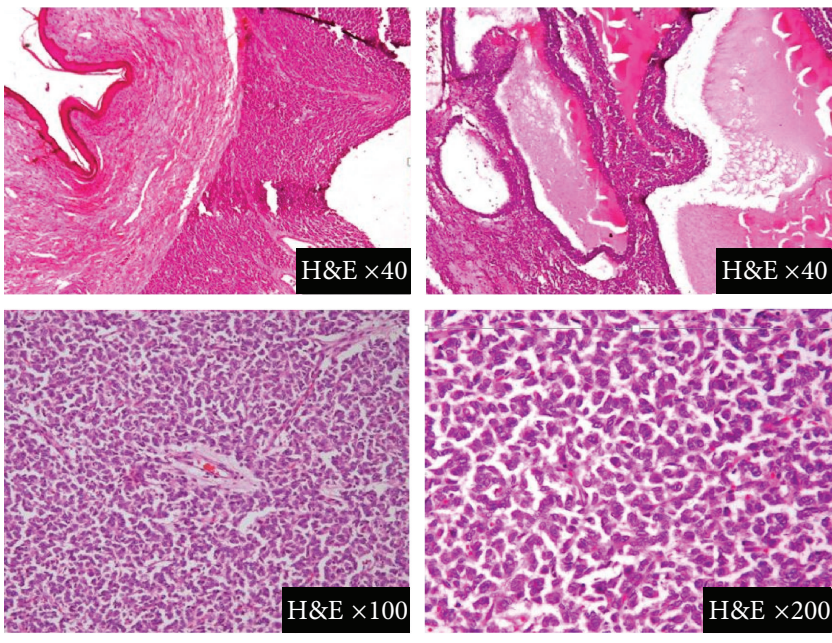

(a)
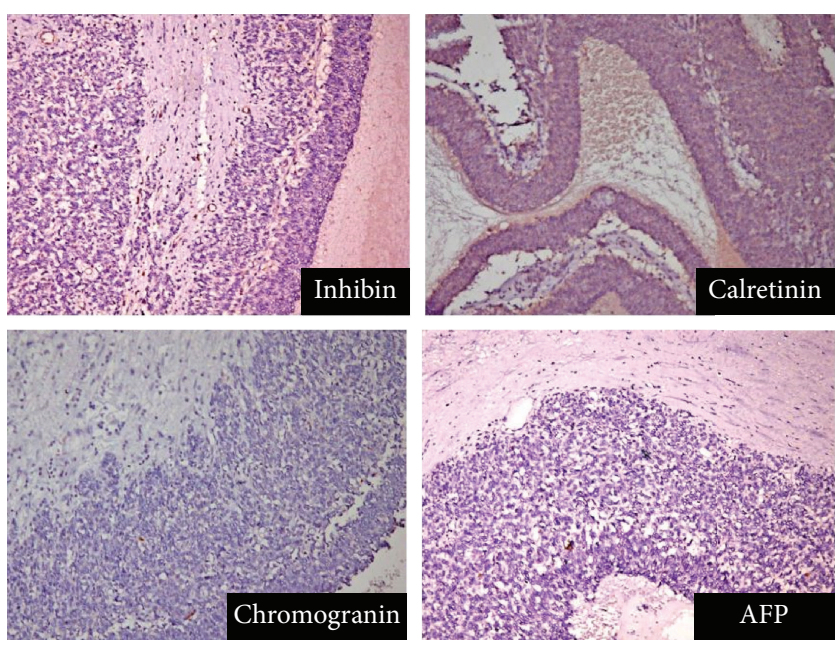

(c)
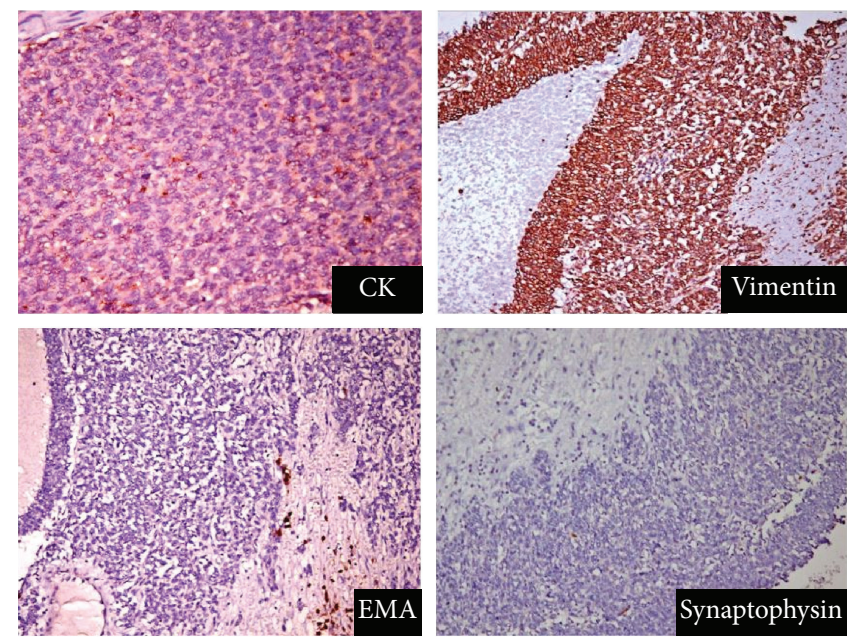

(b)
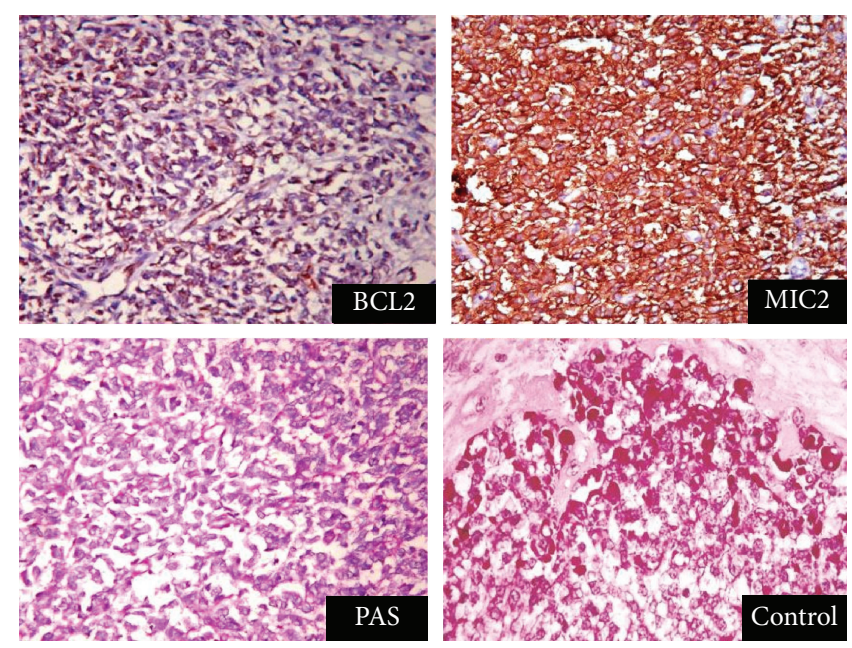

(d)

FIGURE 6: H\&E staining revealed poor differentiation and the tumour was immunopositive for vimentin, cytokeratin (focal), Bcl2, and MIC2.

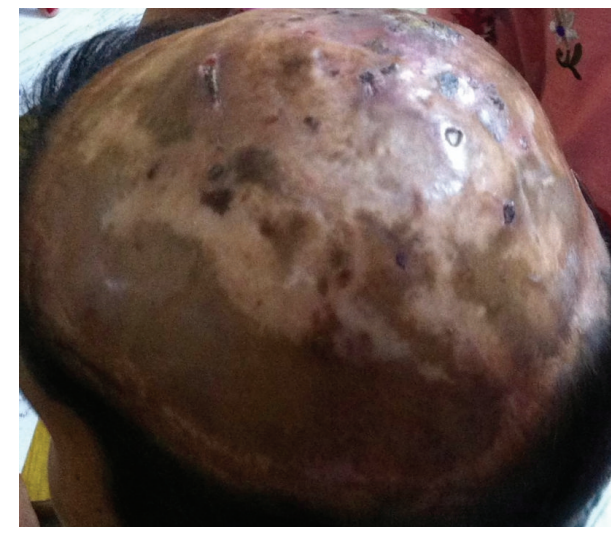

(a)

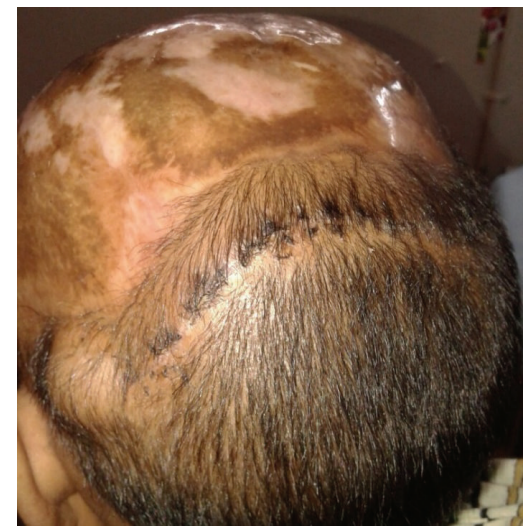

(b)

FIGURE 7: Follow-up showing completely covered scalp tissue (a) and use of tissue expander on the peripheral scalp (containing hair follicles) to cover the bare area (b). 


\section{Consent}

Informed and written consent was obtained from the patient to publish this case report, investigation reports, and images.

\section{Disclosure}

All authors are affiliated to All India Institute of Medical Sciences (AIIMS), New Delhi, and Jai Prakash Narayan Apex Trauma Centre (JPNATC), AIIMS, New Delhi.

\section{Competing Interests}

The authors declare that they have no competing interests.

\section{Authors' Contributions}

Biplab Mishra and Saurabh Singhal headed the team managing this patient. All authors except Saumyaranjan Mallick were involved in the management and follow-up of the patient. Saurabh Singhal wrote the paper. Saurabh Singhal, Biplab Mishra, and Deepak Prakash Bhirud reviewed the literature. All authors read and approved the paper prior to submission. Saumyaranjan Mallick was involved in the extensive histopathology of the specimen. Saurabh Singhal is the corresponding author.

\section{References}

[1] S. Weiss and J. Goldblum, Enzinger and Weiss's Soft Tissue Tumors, CV Mosby, St. Louis, Mo, USA, 2001.

[2] W. J. Harb, M. A. Luna, S. R. Patel, M. T. Ballo, D. B. Roberts, and E. M. Sturgis, "Survival in patients with synovial sarcoma of the head and neck: association with tumor location, size, and extension," Head and Neck, vol. 29, no. 8, pp. 731-740, 2007.

[3] W. Al-Daraji, J. Lasota, R. Foss, and M. Miettinen, "Synovial sarcoma involving the head: analysis of 36 cases with predilection to the parotid and temporal regions," The American Journal of Surgical Pathology, vol. 33, no. 10, pp. 1494-1503, 2009.

[4] J. Barosa, J. Ribeiro, L. Afonso, J. Fernandes, and E. Monteiro, "Head and neck sarcoma: analysis of 29 cases," European Annals of Otorhinolaryngology, Head and Neck Diseases, vol. 131, no. 2, pp. 83-86, 2014.

[5] A. Ketabchi, N. Kalavrezos, and L. Newman, "Sarcomas of the head and neck: a 10 -year retrospective of 25 patients to evaluate treatment modalities, function and survival," British Journal of Oral and Maxillofacial Surgery, vol. 49, no. 2, pp. 116-120, 2011.

[6] N. R. dos Santos, D. R. H. de Bruijn, and A. G. van Kessel, "Molecular mechanisms underlying human synovial sarcoma development," Genes Chromosomes and Cancer, vol. 30, no. 1, pp. 1-14, 2001.

[7] A. Kawai, J. Woodruff, J. H. Healey, M. F. Brennan, C. R. Antonescu, and M. Ladanyi, "SYT-SSX gene fusion as a determinant of morphology and prognosis in synovial sarcoma," The New England Journal of Medicine, vol. 338, no. 3, pp. 153-160, 1998.

[8] H. Inagaki, T. Nagasaka, T. Otsuka, E. Sugiura, N. Nakashima, and T. Eimoto, "Association of SYT-SSX fusion types with proliferative activity and prognosis in synovial sarcoma," Modern Pathology, vol. 13, no. 5, pp. 482-488, 2000.
[9] I. Sultan, C. Rodriguez-Galindo, R. Saab, S. Yasir, M. Casanova, and A. Ferrari, "Comparing children and adults with synovial sarcoma in the surveillance, epidemiology, and end results program, 1983 to 2005: an analysis of 1268 patients," Cancer, vol. 115, no. 15, pp. 3537-3547, 2009.

[10] M. Vlenterie, V. K. Y. Ho, S. E. J. Kaal, R. Vlenterie, R. Haas, and W. T. A. van der Graaf, "Age as an independent prognostic factor for survival of localised synovial sarcoma patients," British Journal of Cancer, vol. 113, no. 11, pp. 1602-1606, 2015.

[11] L. Guillou, J. Benhattar, F. Bonichon et al., "Histologic grade, but not SYT-SSX fusion type, is an important prognostic factor in patients with synovial sarcoma: a multicenter, retrospective analysis," Journal of Clinical Oncology, vol. 22, no. 20, pp. 40404050, 2004.

[12] P. Bergh, J. M. Meis-Kindblom, F. Gherlinzoni et al., "Synovial sarcoma. Identification of low and high risk groups," Cancer, vol. 85, no. 12, pp. 2596-2607, 1999.

[13] A. Ferrari, A. Gronchi, M. Casanova et al., "Synovial sarcoma: a retrospective analysis of 271 patients of all ages treated at a single institution," Cancer, vol. 101, no. 3, pp. 627-634, 2004.

[14] P. Jernstrom, "Synovial sarcoma of the pharynx: report of a case," American Journal of Clinical Pathology, vol. 24, no. 8, pp. 957-961, 1954.

[15] F. R. Amble, K. D. Olsen, A. G. Nascimento, and R. L. Foote, "Head and neck synovial cell sarcoma," Otolaryngology-Head and Neck Surgery, vol. 107, no. 5, pp. 631-637, 1992.

[16] R. A. Salcedo-Hernández, L. S. Lino-Silva, and K. Luna-Ortiz, "Synovial sarcomas of the head and neck: comparative analysis with synovial sarcoma of the extremities," Auris Nasus Larynx, vol. 40, no. 5, pp. 476-480, 2013.

[17] B. M. Shmookler, F. M. Enzinger, and R. B. Brannon, "Orofacial synovial sarcoma. A clinicopathologic study of 11 new cases and review of the literature," Cancer, vol. 50, no. 2, pp. 269-276, 1982.

[18] J. J. Lewis, C. R. Antonescu, D. H. Y. Leung et al., "Synovial sarcoma: a multivariate analysis of prognostic factors in 112 patients with primary localized tumors of the extremity," Journal of Clinical Oncology, vol. 18, no. 10, pp. 2087-2094, 2000.

[19] R. De Bree, I. Van Der Waal, E. De Bree, and C. René Leemans, "Management of adult soft tissue sarcomas of the head and neck," Oral Oncology, vol. 46, no. 11, pp. 786-790, 2010. 


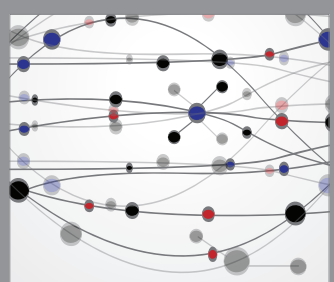

The Scientific World Journal
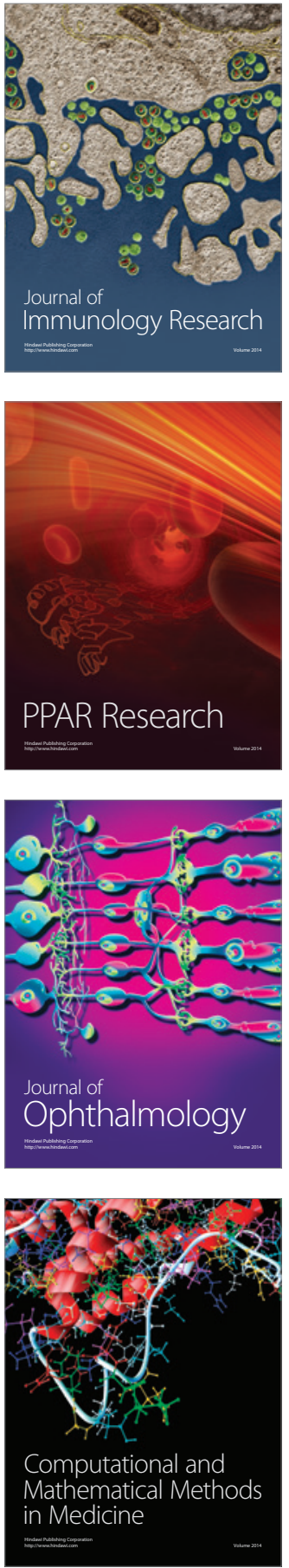

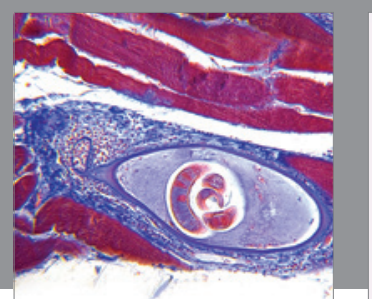

Gastroenterology Research and Practice

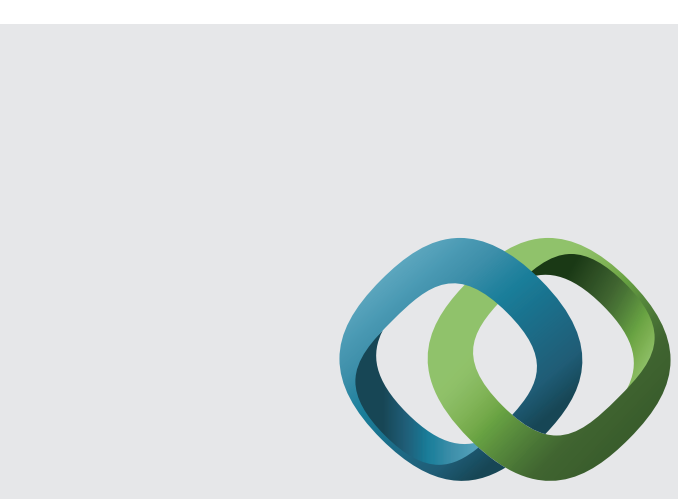

\section{Hindawi}

Submit your manuscripts at

http://www.hindawi.com
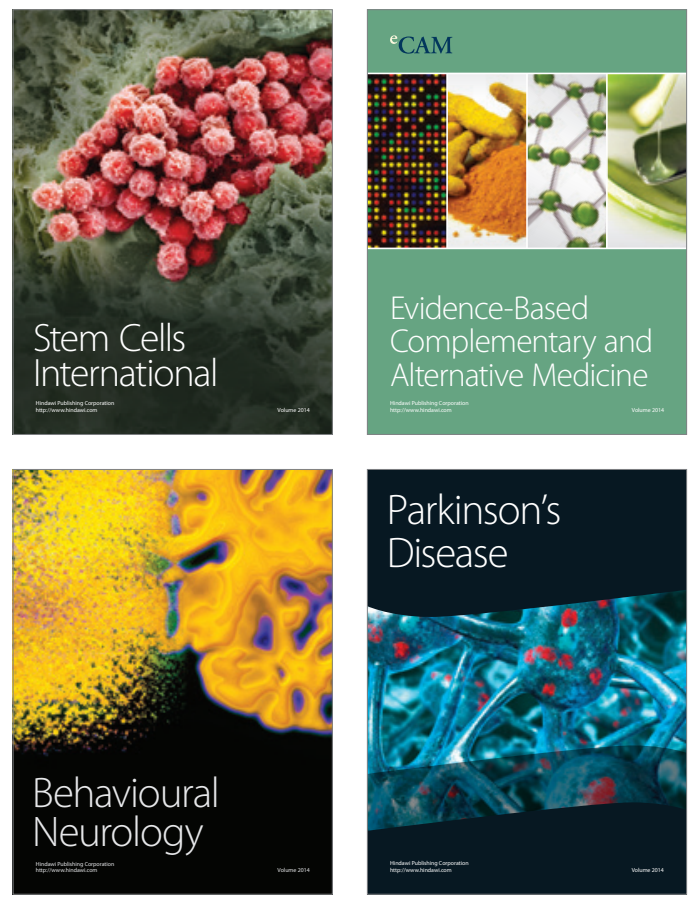
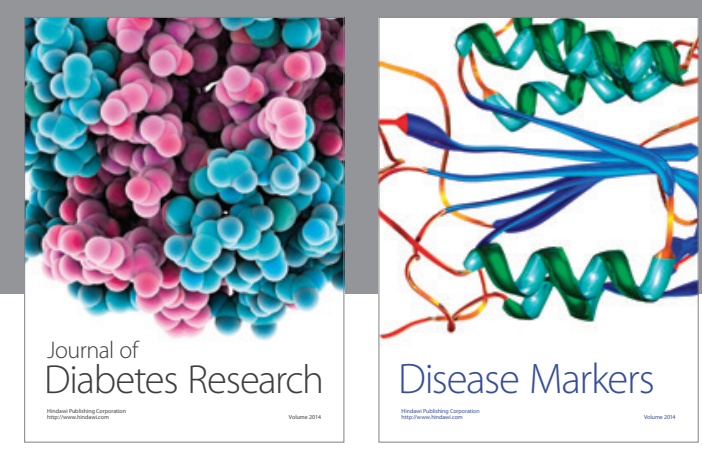

Disease Markers
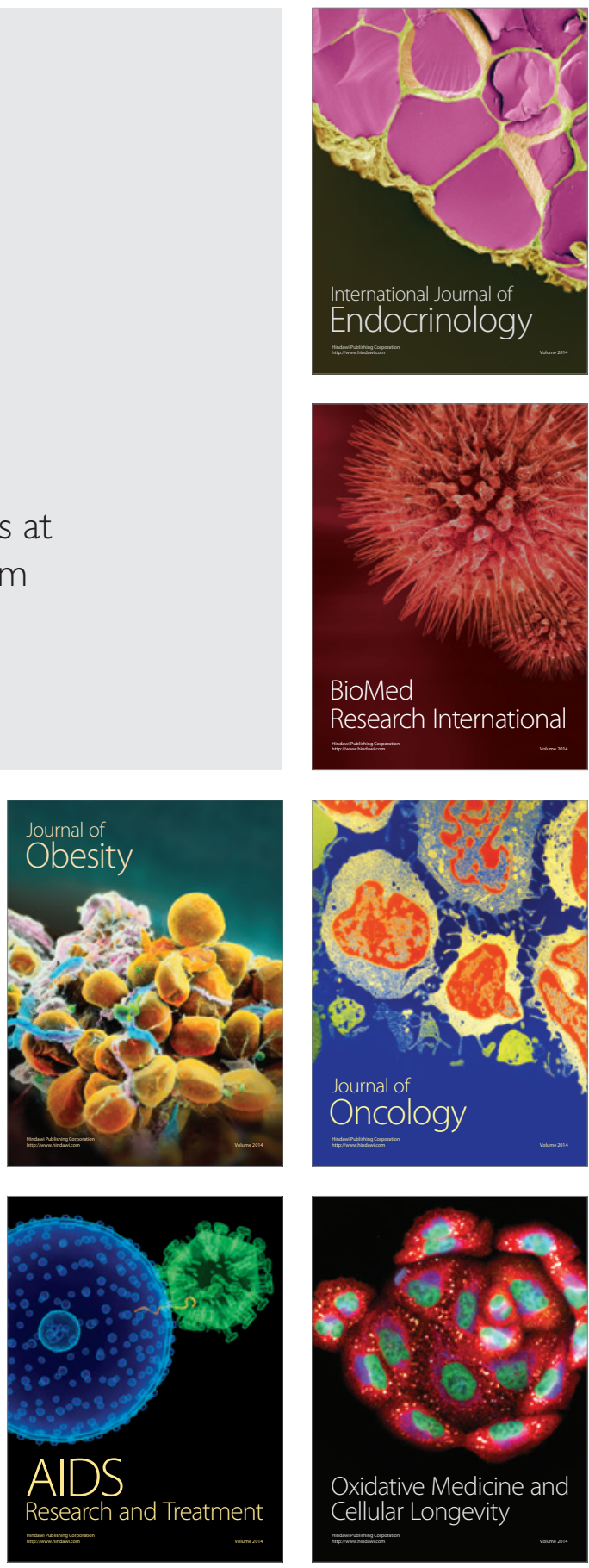